\title{
Mean Normal Portal Vein Diameter Using Sonography among Clients Coming to Radiology Department of Jimma University Hospital, Southwest Ethiopia
}

\author{
Gemechu Geleto ${ }^{1}$, Wondim Getnet ${ }^{1}$, ${\text { Tsegaye } \text { Tewelde }^{2}}^{2}$
}

\author{
ABSTRACT
}

BACKGROUND: Mean portal vein diameter is considered as the best indicator for portal hypertension. However, the cutoff point differs from study to study (above 10-15 mm) despite the existence of normal mean portal vein diameter between 10-15 $\mathrm{mm}$ in different settings.This implies the existence of limited evidence on normal portal vein diameter for all populations in all countries prior to setting the cutoff points. Therefore, the aim of this study was sonographic assessment of normal mean portal vein diameter among patients referred to The Department of Radiology in Jimma University Hospital.

METHODS: A facility based cross-sectional study was conducted from November to December 2014 at Jimma University Hospital on a total of 195 clients. Data about portal vein diameter for eligible clients were collected by radiologists using Sonography. Data were edited manually, entered and analyzed using SPSS version 16.

RESULT: Data were collected from a total of 195 participants. Among these, 121(62.1\%) were males and the median age of the participants was 35 years. The study revealed a normal mean portal vein diameter of $10.6 \mathrm{~mm} \pm 1.8 \mathrm{SD}$ with a respirophasic variation of $25.6 \%$. Likewise, the normal mean portal vein diameter seemed to have varied significantly by age and sex.

CONCLUSION: The study revealed a normal mean portal vein diameter ranging below $13 \mathrm{~mm}$. Hence, decisions made in clinical settings should base on these findings. Besides, there is a need for large scale study to determine portal vein diameter variation by age and sex, controlling other confounders.

KEYWORD: Portal vein diameter, Mean, Portal hypertension, Sonography, Ethiopia

DOI: http://dx.doi.org/10.4314/ejhs.v26i3.6

\section{INTRODUCTION}

Portal vein is a special conduit which transmits blood from the capillaries of intestinal wall and spleen to capillaries of hepatic sinusoids $(1,2)$. The most common abnormality of this special conduit (portal venous system) is portal hypertension (2).

Portal hypertension is a prevalent clinical syndrome defined as an increase in portal venous pressure, and this leads to in impendence of blood flow through the vein into the hepatic circulation (2-5). The most common causes of portal hypertension cited in different studies were cirrhosis (in developed countries) $(6,7)$, schistosomiasis (in endemic areas) (8) and hepatic vascular abnormalities (4). As a result of portal hypertension, dilatation of portal vein, splenomegaly and formation of portal systemic collaterals at different sites are consequently developed. Hence,it leads to high mortality and morbidity because it is the most common complication and leading reason for deaths among clients with chronic liver disease $(2,6,7)$. Regardless of the types of causes, the complications (consequences) of portal hypertension are similar $(6,7)$.

Since many centuries ago, there were trials for the development of portal hypertension measuring tools (Ultrasound) among which Grayscale Ultrasound (US), Doppler US and Sonography were better sensitive and specific

\footnotetext{
${ }^{\mathrm{T}}$ Department of Radiology, College of Health Sciences, Jimma University, Ethiopia

${ }^{2}$ Department of Epidemiology and Biostatistics, College of Health Sciences, Jimma University, Ethiopia

Corresponding Author: Tsegaye Tewelde, Email: tsegaye.tewelde@yahoo.com
} 
ones $(2,7,9)$. Although Gray-scale and Doppler US allow anatomic and functional evaluations of the major tributaries of the portal venous system (9), Sonography is non-ionizing, easily accessible, non-invasive and portable in nature, reliable, low in cost and also it is rapid. These features make Sonography a good diagnostic tool for portal hypertension $(4,7,10,11)$.

The normal portal vein diameter (PVD) can vary normally between 7 to $15 \mathrm{~mm}$ while normal portal venous pressure lies between 5 and 10 $\mathrm{mmHg}(14 \mathrm{~cm}$ of $\mathrm{H} 2 \mathrm{O})$ (12). If portal venous pressure is more than $15 \mathrm{mmHg}(30 \mathrm{~cm}$ of $\mathrm{H} 2 \mathrm{O})$, then it might indicate portal hypertension (12). A portal vein diameter greater than $13 \mathrm{~mm}$ is assumed to be the cutoff point for portal hypertension in the appropriate clinical setting (4$6,13)$. On the contrary, a portal vein diameter greater than $10 \mathrm{~mm}$ was also considered as portal hypertension in previous literatures $(2,7,14)$. However, mean normal portal vein diameter greater than $10 \mathrm{~mm}$ was also indicated from previous studies: $13 \mathrm{~mm}$ (15), greater than $11 \mathrm{~mm}$ in Nigeria (2), $11.54 \mathrm{~mm}$ in Kolkata (6), which contradicts with the mentioned cutoff point.

These imply the existence of limited evidence on normal portal vein diameter for all populations in all countries of the world prior to setting the cutoff points. On top of this, the need for having scientific evidence on mean portal vein diameter among normal and with portal hypertensive clients in all countries was cited by literatures $(2,7)$.

To the investigators' knowledge, there was a single study on mean normal portal vein diameter using Sonography in the Ethiopian context set up (7). However, it was conducted on the country's highest specialized referral hospital, in which patients are usually presented with severe and complicated diseases. Hence, these clients might not represent relatively healthy, mild and moderately ill clients in all corners of the country. Likewise, schistosomiasis (a known cause for portal hypertension) was also prevalent $(26.3 \%$ ) in the study area (16). Thus, health professionals may encounter repeated difficulties in deciding portal hypertension. Therefore, the aim of this study was to estimate the mean normal portal vein diameter using Sonography among clients coming to the Radiology Department of Jimma university Hospital, Southwest Ethiopia.

\section{METHODS AND MATERIALS}

Study setting: Data were collected in Jimma University Hospital from November 1, 2014 December 12, 2014 on patients waiting to have diagnostic imaging at Radiology Department of Jimma University Hospital, Jimma Town, Southwest Ethiopia. Jimma Town is located in Southwest Ethiopia, $335 \mathrm{~km}$ from Addis Ababa, the capital city of the country. The hospital serves for over 15 million people in Southwest Ethiopia (17). There were two x-ray machines, one fluoroscopy and three functional ultrasounds (one Doppler ultrasound) in the Radiology Department of the hospital.

Study design: Institution based cross-sectional study was utilized.This was selected because the study was aimed at measuring the normal portal vein diameter of clients at a certain point in time, a snap shot measurement.

Participants: All eligible adult patients refered from all departments of the hospital for routine diagnostic abdominal sonographic scanning were included to the study. For a patient to be included in the study, he/she (i) had to fast for any food for at least six hours (ii) had no the clinical diagnosis or sonographic features suggesting the presence of hepato-biliary disease (iii) should not be a pregnant women and (iv) had no hepato-biliary surgery or recent surgery for other reasons. Hepato-biliary disease indicate any of the following problems, patient with hypertension, diabetes mellitus and/or cardiac disease.

Sampling procedure: A total of 195 patients who fulfilled the eligibility criterion and came to the Radiology Unit within the specified study period were consecutively included into the study. Howevere, resource was too limited to extend the number of participants.

Measurement: Before specific measurement of the portal vein diameter, routine scanning was done to check for the eligibility criteria using Sonographic criteria, asking for symptoms, conducting physical examination, reviewing cards and asking questions about fasting. Then, eligible clients were asked their age and filled their sex on a prepared checklist. With regard to the standard operative procedure of LOGIQ P6R3.5MHZ convex probe Sonography, the patient was scanned in supine and right anterior oblique position with the transducer in the oblique position 
in the RUQ of the abdomen. Measurement of the portal vein diameter was taken in quiet respiration at the hilum of the liver just before bifurcation into right and left. The diameter was taken by putting the two cursors in the internal wall of the portal vein; the wall of the portal vein was excluded from the measurement.

With respect to portal vein diameter variation with phases of respiration, the measurement was made during inspiration, expiration and quiet state. Then, the findings of the Sonography were filled in the checklist. Respirophasic variation was calculated as deep inspiratory minus deep expiratory and divided by mean deep inspiratory PVD multiplied by $100 \%$. Respirophasic variation was considered normal if above 20\%. Normal mean portal vein diameter was the average of mean deep inspiration and expiration. Variables like normal portal vein diameter in $\mathrm{mm}$, portal vein diameter during phases of respiration, age, and sex were included in this study.

Data were collected by two radiologists working in the Radiology Unit, and all the investigators were assigned as supervisors. Half day training and discussion was made with the radiologists to reach consensus about the standard operative procedure of Sonography. Supervision was made by the investigators during the data collection to ensure data quality.

Data processing and analysis: Data were edited manually before entry to a computer and then entered to SPSS version 16. Thereafter, it was cleaned, coded and analyzed. Descriptive analysis was computed to calculate mean and standard deviation of normal portal vein diameter as well as age. Percentage change in portal vein diameter during phases of respiration as well as proportion of clients lay under age and sex categories were computed. Result was presented in the form of tables and figure.

Ethical consideration: Ethical clearance was obtained from the Ethical Board of the College of Public Health and Medical Sciences of Jimma University. Oral consent was obtained from the study participants after the consent form was developed by the research team and approved by the ethical committee of Jimma University. Similarly, all the information gathered from the clients was handled confidentially, and it was used only for research purpose. Care was taken not to interfere with the normal radiologic services given in the department. Clients found victims of portal hypertension during screening for eligible participants were counseled and linked with the Internal Medicine Department for further care.

\section{RESULT}

Mean portal vein diameter and its distribution by age and sex: Data were collected from a total of 195 participants, among these, 121(62.1\%) were males. The median age of the partcipants was 35 years. Near to twenty nine percent, $18.5 \%$ and $12.8 \%$ of the participants were in the age categories of 21-30, 51-60 and 11-20 years respectivly (Table 1).

Table 1: Mean portal vein diameter distribution by age and sex at Jimma university Hospital ( $\mathrm{n}=195)$, South West Ethiopia, 2014.

\begin{tabular}{llllll}
\hline Variables & Category & $\mathrm{N}(\%)$ & Mean PVD \pm SD & F-test & P-value \\
\hline Age (in years) & $\leq 10$ & $13(6.7)$ & $7.9 \pm 1.6$ & 8.20 & 0.001 \\
& $11-20$ & $25(12.8)$ & $9.7 \pm 2.05$ & & \\
& $21-30$ & $56(28.7)$ & $11.08 \pm 1.4$ & & \\
& $31-40$ & $26(13.3)$ & $10.7 \pm 1.6$ & & \\
& $41-50$ & $17(8.7)$ & $11.3 \pm 1.6$ & & \\
& $51-60$ & $36(18.5)$ & $10.9 \pm 1.7$ & & \\
& $61-70$ & $7(3.6)$ & $9.9 \pm 1.0$ & & \\
& $\geq 71$ & $15(7.7)$ & $10.8 \pm 1.5$ & & \\
& Total & $195(100.0)$ & $10.60+1.8$ & & \\
\hline sex & & & t-test & P-value \\
& Male & $121(62.1)$ & $10.9+1.9$ & 3.63 & 0.001 \\
& Female & $74(37.9)$ & $10.00+1.5$ & & \\
& Total & $195(100)$ & $10.6 \pm 1.8$ & & \\
\hline
\end{tabular}

PVD portal vein diameter, SD standard deviation 
The normal mean portal vein diameter $( \pm S D)$ was $10.6 \mathrm{~mm} \pm 1.8 \mathrm{SD}$. The result showed an increment of mean portal vein diameter from the age less than 10 years up to 30 years. The mean portal vein diameter was $11.3 \mathrm{~mm} \pm 1.6$ in the age category of 41-50 years and $7.9 \mathrm{~mm} \pm 1.6$ in less than 10 years children. The normal mean portal vein diameter in males was $10.9 \mathrm{~mm}+1.9$ and $10.0 \mathrm{~mm} \pm 1.5$ in females. Moreover, the normal mean portal vein diameter differed by age $(\mathrm{F}=8.20, \mathrm{P}<0.001)$ and $\operatorname{sex}(\mathrm{t}=3.60, \mathrm{P}<0.001)$ significantly (Table 1$)$.
Normal mean portal vein diameter variation by respiratory phases: Table 2 shows the comparison of normal mean portal vein diameter in case of quiet, deep inspiration and deep expiration. In that, the mean \pm SD of deep inspiration was $12.1 \pm 1.9 \mathrm{~mm}, 9.0 \pm 1.9 \mathrm{~mm}$ during deep expiration and $10.3 \pm 1.8 \mathrm{~mm}$ during quite respiration (Table 2).

Table 2: Mean portal vein diameter during quite, deep inspiration and deep expiration at Jimma University Hospital $(n=195)$, South West Ethiopia, 2014.

\begin{tabular}{lllllll}
\hline & Male & & \multicolumn{2}{l}{ Female } & Total \\
\hline Variables & $\mathrm{N}$ & Mean PVD \pm SD & $\mathrm{N}$ & Mean PVD \pm SD & $\mathrm{N}$ & Mean PVD \pm SD \\
During Quite & 121 & $10.60 \pm 1.90$ & 74 & $9.80 \pm 1.60$ & 195 & $10.3 \pm 1.8$ \\
During deep inspiration & 121 & $12.5 \pm 2.00$ & 74 & $11.60 \pm 1.70$ & 195 & $12.1 \pm 1.9$ \\
During deep expiration & 121 & $9.30 \pm 2.00$ & 74 & $8.40 \pm 1.50$ & 195 & $9.0 \pm 1.9$ \\
\hline
\end{tabular}

$\mathrm{N}$ is number of respondents

Respirophasic variation of mean portal vein

diameter: With respect to the respirophasic

variation of normal portal vein diameter, the highest was among females $(27.6 \%)$ but it was $25.6 \%$ in both male and female (Figure 1).

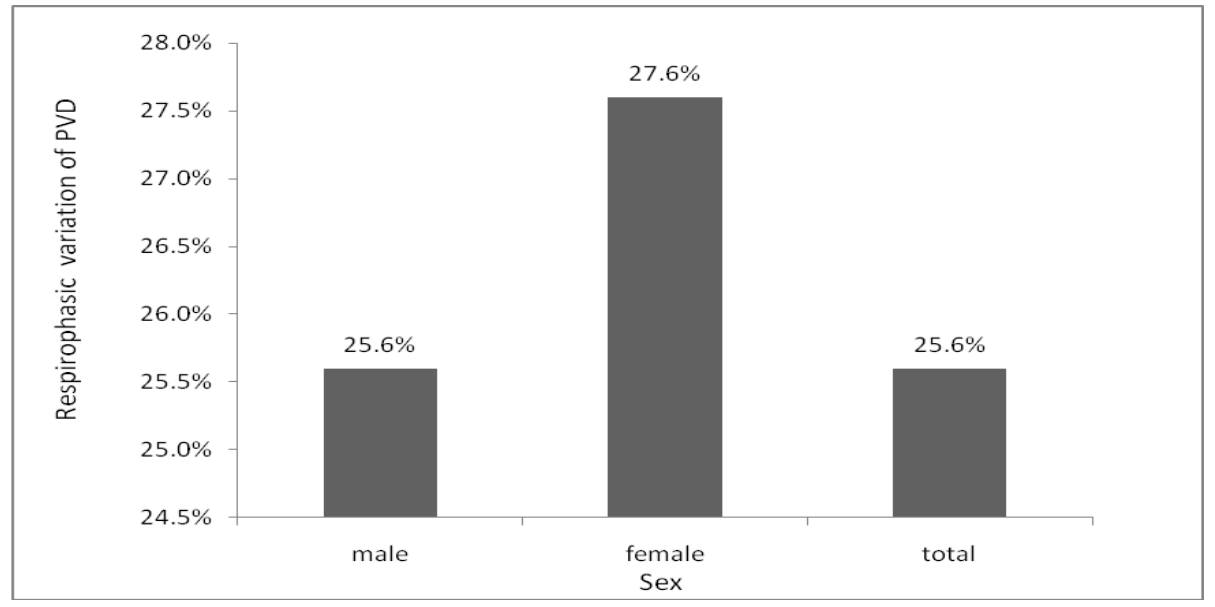

Figure 1: Respirophasic variation of mean portal vein diameter at Jimma University hospital, South West Ethiopia, 2014

\section{DISCUSSION}

This study was aimed at assessing using Sonography the normal mean portal vein diameter and its distribution by age and sex. The study revealed a normal mean portal vein diameter of $10.6 \mathrm{~mm} \pm 1.8 \mathrm{SD}$ with a respirophasic variation of
$25.6 \%$. In addition, the normal mean portal vein diameter seemed to have varied by age and sex.

The normal mean portal vein diameter in our setting was $10.6 \mathrm{~mm} \pm 1.8 \mathrm{SD}$ which is in agreement with other studies done in USA (11 $\mathrm{mm} \pm 2 \mathrm{SD}$ ) (5), Nigeria (11.45 $\mathrm{mm} \pm 1.49 \mathrm{SD})(2)$, and Kolkata (11.54 mm) (6). However, our finding is inconsistent with the finding of a study done in Addis Ababa, Ethiopia (7.9 mm $\pm 2 \mathrm{SD}$ ) (7). The 
discrepancy could be due to ethnic differences because the setting of this study is located in Oromiya Region where most of the participants in our study were possibly Oromo in ethnicity unlike participants who were possibly from all ethnic groups of Ethiopia in the study carried out in Addis Ababa. On top of this, mean portal vein diameter was significantly greater in males than in females in this study. Male participants were higher in this study (62\%) than study done in Addis Ababa (38\%). Hence, the variation could be due to the participants' sex.

The respirophasic variation of mean portal vein diameter was $25.6 \%$, which shows a normal mean portal vein diameter increase during inspiration that is above the cutoff point (20\%). Clients below $20 \%$ in respirophasic variation of mean PVD are suspected to have portal hypertension $(4,7)$. However, the finding of this study was slightly higher than a study done in Addis Ababa, Ethiopia (21.5\%) (7). However, the implications of mean portal vein diameter and respirophasic variation in this study seem contradictory with the findings in Addis Ababa, Ethiopia. This might be due to the loose indication of average portal vein diameter for portal hypertension as compared to increase in portal vein diameter during deep inspiration (18).

In addition, the mean portal vein diameter seemed to have varied significantly with age $(\mathrm{F}=8.20, \mathrm{P}<0.001)$ and $\operatorname{sex}(\mathrm{t}=3.60, \mathrm{P}<0.001)$. There was a consistent finding with respect to mean portal vein diameter variation by age in previous studies done in India (12), USA (5), Nigeria (2) and Addis Ababa, Ethiopia (7). Previous studies done in West Bengal (6), India (12) and Addis Ababa, Ethiopia (7) identified that mean PVD did not vary by sex although no statistical tests were done.

This study could have its own limitation in that, the role of confounding factors in determining the mean portal vein diameter variation by age and sex was not controlled. Hence, interpretation and utilization of the findings should be made with care. In conclusion, the study revealed a normal mean portal vein diameter ranging below $13 \mathrm{~mm}$ with a normal respirophasic variation (above the cutoff point for portal hypertension). In addition, the normal mean portal vein diameter seemed varied by age and sex. Hence, decisions made in clinical settings should base on these findings. Besides there is a need for large scale study to determine mean portal vein diameter variation by age and sex, controlling other confounders.

\section{ACKNOWLEDGMENT}

Our earnest gratitude goes to Jimma University for the financial support for the data collection phase of this research. Jimma University Specialized Hospital and Radiology Department for the coordination of the data collection. Finally, we would like to thank all staffs of the department, data collectors and study participants for their valuable cooperation and assistance.

\section{REFERENCES}

1. Ekta G, Nema U, Gupta A. Sonographic Evaluation Of Portal Vein Diameter In North Indian Population. NJIRM, 2013; 4(2)

2. Anakwue AC, Anakwue RC, Ugwu AC, Nwogu UB, Idigo FU, Agwu KK . Sonographic Evaluation of Normal Portal Vein Diameter in Nigerians. European Journal of Scientific Research, 2009; 36(1):114-7.

3. Ong JP, Sands M, Younossi ZM. Transjugular intrahepatic porto systemic shunts (TIPS): a decade later. J Clin Gastroenterol, 2000; 30(1):14-28.

4. Al-Nakshabandi NA. The Role of Ultrasonography in Portal Hypertension. The Saudi Journal of Gastroenterology, 2006; 12(3):111-7.

5. Weinreb J, Kumari S, Phillips G, Pochaczevsky R.Portal vein measurements by real-time sonography. AJR Am J Roentgenol, 1982; 139(3):497-9.

6. Lopamudra M, Sanjay K M, Dipanjan B, Datta S. Correlation of portal vein diameter and splenic size with gastro-oesophageal varices in cirrhosis of liver. JIACM, 2011; 12(4):266-70.

7. Hawaz Y, Admassie D, Kebede T. Ultrasound Assessment of Normal Portal Vein Diameter in Ethiopians Done at Tikur Anbessa Specialized Hospital. East and central African journal of surgery, 2012; 17(1)

8. Ohmae $\mathrm{H}$, Tanaka M, Hayashi $\mathrm{M}$, et al. Improvement of ultrasonographic and serologic changes in Schistosoma japonicum- 
infected patients after treatment with praziquantel. Am J Trop Med Hyg, 1992; 46(1):99-104.

9. Lee WK, Chang SD, Duddalwar VA, et al. Imaging assessment of congenital and acquired abnormalities of the portal venous system. Radiographic, 1148; 31(4):905-26.

10. Nestaiko OV, Iarovoi AV, Bekov AD. UltraSonographicsymptoms ofportal hypertension. Med Radiol, 1991; 36(2):4-6.

11. Webb LJ, Berger LA, Sherlock S. Grey-scale ultrasonography of portal vein. Lancet, 1977; 2(8040):675-7.

12. Ravi SG, Shailaja S, Srinath MG, Kulkarni R. Estimation of Portal Vein Diameter in co Relation with the Age, Sex and Height of An Individual. Anatomica Karnataka, 2011; 5(2):13-6.

13. Pinto-Silva RA, Queiroz LC, Azeredo LM, Silva LC, Lambertucci JR. Ultrasound in schistosomiasis mansoni. Mem Inst Oswaldo Cruz, 105(4):479-84.

14. Bolondi L, Gandolfi L. Ultrasonography in assessment of portal venous system: Lancet. 1978 Mar 25; 1(8065):656-7.
15. Schabel SI, Rittenberg GM, Javid LH, Cunningham J, Ross P. The "bull's-eye" falciform ligament: a sonographic finding of portal hypertension. Radiology, 1980; 136(1):157-9.

16. Mengistu M, Shimelis T, Torben W, Terefe A, Kassa T, Hailu A. Human intestinal schistosomiasis in communities living near three rivers of Jimma town, South Western ethiopia. Ethiop J Health Sci, 21(2):111-8.

17. Jimma University: Jimma University specialized Hospital (JUSH).Available from:http://www.ju.edu.et/jimma-universityspecialized-hospital-jush, Accessed September 2014.

18. Dach JL, Hill MC, Palaez JC, LePage JR, Russell E. Sonography of hypertensive portal venous system: correlation with arterial portography. AJR Am J Roentgenol, 1981; 137(3):511-7. 